\title{
The positive impact of physical activity on the reduction of anxiety scores: a pilot study
}

\author{
DDalton Gonçalves Lima Alves ${ }^{1}$ \\ (iD Silvia Gabrielli Rocha ${ }^{1}$ \\ (D) Evandro Vitor Andrade \\ (iD) Augusto Zbonik Mendes ${ }^{1}$ \\ (iD) Ângelo Geraldo José Cunha
}

1. Academics in the Medical Program of the Metropolitan Institute of Higher Education/IMES - Univaço, Ipatinga, Minas Gerais, Brasil 2. Professor of the Medical Program of the Metropolitan Institute of Higher Education/IMES - Univaço, Ipatinga, Minas Gerais, Brasil

http://dx.doi.org/10.1590/1806-9282.65.3.434

\section{SUMMARY}

OBJECTIVES: To compare anxiety scores between physical activity practitioners and sedentary, men and women and to relate them to physical activity frequency and age.

METHODS: In this cross-sectional study, a sample of 256 regular aerobic physical activity practitioners was compared to a sample of 256 sedentary individuals (control group). Anxiety scores were quantified by Anxiety Inventory Spielberger State-Trait (STAI). The scores of the groups were compared using the Student t-test and chi-square test for parametric and non-parametric data, respectively. The correlation between scores of different variables was performed using the Pearson test.

RESULTS: There was a significant difference between the average anxiety scores $(p<0.001)$ and the chi-square test proved there is a higher prevalence of severe anxiety $(p<0.001)$ in the sedentary group. Age did not correlate with worse anxiety scores $(p<0.05)$. Comparing by gender, women had a higher prevalence of intense anxiety.

CONCLUSIONS: Individuals who engage in regular physical activity have lower levels of anxiety, and both sexes are benefited with the anxiolytic potential of physical activity. Therefore, this study proved that the Roman poet Juvenal was right, and his expression "Mens sana in corpore sano," could also be interpreted in the opposite direction, i.e., a healthy body correlates with a healthy mind.

KEYWORDS: Anxiety. Exercise. Sedentary lifestyle. Psychiatry.

\section{INTRODUCTION}

According to Plato (4th century BCE), "In order for man to succeed in life, God gave him two means, education and physical activity, one for the soul, the other for the body. It is only with just these two means together that man can reach perfection". In the 1st century A. D., the Roman poet Juvenal coined the famous quote "Mens sana in corpore sano'. To him, physical activity was considered the key to keeping our body and our mind in a state of healthy balance. ${ }^{2}$

The World Health Organization ${ }^{3}$ estimated that physical inactivity is the fourth risk factor for overall mortality, ahead of overweight and obesity. Recent studies suggest that the practice of a minimum of daily physical activity is able to reduce mortality from all causes in up to $19 \%{ }^{4}$

The association between sedentary behavior and mental disorders, such as depression and low self-esteem, has been reported in some population groups, such as women and adolescents ${ }^{5}$. According to Almeida ${ }^{6}$, anxiety is a warning sign that allows indi-

DATE OF SUBMISSION: 04-Jun-2018

DATE OF ACCEPTANCE: 20-Jun-2018

CORRESPONDING AUTHOR: Ângelo Cunha

Rua João Patricio De Araujo, 179 - Bairro Veneza - Ipatinga

Minas Gerais - Brasil - CEP 35164-251 - Tel: (31) 9632-8043

E-mail: angelogeraldojose@hotmail.com 
viduals to be aware and take the necessary measures to deal with this threat. In its pathological form, it is an inadequate response to certain stimuli, due to its intensity or duration. The diagnosis of pathological anxiety can be achieved by means of well-established criteria, such as those of the American Psychiatric Association, through the 5th edition of the Diagnostic and Statistical Manual of Mental Disorders (DSM-V), or the World Health Organization, the 10th edition of the International Statistical Classification of Diseases and Related Health Problems (ICD-10). Moreover, the quantification of anxiety can be done using validated questionnaires, such as the Spielberger and Hamilton, which are the most used, including their versions in Portuguese.

The scientific evidence of the benefits of physical activity on mental health has been increasing significantly. Meta-analyses and systematic reviews have shown the benefits of different forms of physical activity in adults with anxiety disorders, with results as effective as pharmacotherapy and/or cognitive-behavioral therapy. ${ }^{7}$

Therefore, it is increasingly clear the association between the regular practice of physical activity and the improvement of psychiatric symptoms related to humor. The objective of this study was to quantify anxiety scores in a sample of individuals who practice physical activity regularly, comparing it to a sample of sedentary individuals. In addition, we verified whether there are inter-relationships between the variables (age, sex, and frequency of physical activity) in the results found. Therefore, we sought evidence that can prove that there is an association between "Healthy Body, Healthy Mind."

\section{METHODS}

The research was approved by the Research Ethics Committee of the University Center of East Minas Gerais - Unileste under decision No. 1,165.392, on 07/27/2015.

This is an observational study with a cross-sectional design conducted in the city of Ipatinga, MG. Since there are no data in the literature about anxiety scores for this municipality, to estimate the sample size in the present study, we employed the technique of sampling for convenience described by Portney and Watkins ${ }^{8}$. It uses a test sample, in which individuals are selected according to availability, by means of continuous recruitment of subjects until the minimum number that allows for the statistical analysis proposed is reached. According to Motta, in quantitative studies, samples that have a minimum of 30 subjects can represent with good accuracy the population average. ${ }^{9}$

The sample was composed of 512 individuals, 256 who practiced physical activity regularly (active group) and 256 sedentary (control group).

The criteria for inclusion in the active group were adults (18-60 years), of both sexes, healthy, who practiced physical activity regularly, of the aerobic type, following the criteria of the American Heart Association (AHA) for defining physically active: minimum of 25 minutes of intense activity for three or more times per week or a minimum of 30 minutes of moderate activity for five or more times per week. ${ }^{10}$

In the control group, we included adults (18-60 years) of both sexes, healthy, who did not practice physical activity on a regular basis.

Among the exclusion criteria for both groups were individuals with diagnosis and/or treatment for physical and/or mental conditions.

The recruitment occurred in recreational clubs and gyms of Ipatinga, as well as during sporting events in the municipality.

The selection of participants was made via a direct approach by the researchers. After clarification about the research, each individual who agreed to participate in the project was approached by the researchers, who then evaluated the inclusion and exclusion criteria and forwarded the volunteers to a place to carry out the assessment individually. At this place, they were given all the necessary information and were asked to sign the Informed Consent Form (ICF).

The anxiety symptoms were assessed and quantified using the State-Trait Anxiety Inventory, proposed by Spielberger in 1970, translated and standardized for Portuguese. ${ }^{11}$ It is a self-assessment questionnaire in the form of two scales that allow the level of anxiety symptoms to be graded: state and trait. The term state-anxiety means anxiety concerning the present moment (the application of the questionnaire), while trait-anxiety refers to a personality tendency that does not vary with time. The trait scale was used in this study.

This scale consists of 20 statements that individuals use to describe themselves. Each affirmation receives a score of one to four and the values of all items are then added up. Those in which the high 
score indicates low anxiety, the value of the score is reversed. For both scales, the following results apply: mild anxiety (less than or equal to 33 points); moderate anxiety (from 34 to 48 points); severe anxiety (greater than or equal to 49 points).

Since this is a self-assessment questionnaire, each individual first received instructions about its correct filling out and then received the questionnaire to read and answer. The interviewer was available for clarification of possible doubts.

For the statistical analysis, initially, the demographic data for each sample (age and sex) was described. Then the profiles of the sample of assets regarding the type of physical activity, as well as its weekly frequency, were described.

For anxiety scores, an analysis of the difference between the averages of the groups was performed using the Student's t-test for independent samples.

Considering the sample size of the present study, for 510 of freedom[(n1 - 1) + (n2 - 1)], the statistical difference should be considered significant when $t$ $>1.96$ for significance $(\alpha)$ of 0.05 in samples of twotailed distribution. ${ }^{9}$

To estimate the difference of qualitative data, we used the Pearson chi-square test $\left(X^{2}\right)$, a nonparametric test of significance that deals essentially with the discrepancies between the observed and expected frequencies. ${ }^{9}$

The correlation between age and anxiety scores was assessed using the Pearson Correlation Coefficient, considered to be relevant when greater than 0.3. ${ }^{8}$ This coefficient was also used to estimate the correlation between the frequency of physical activity and anxiety scores.

To estimate the associations between sedentary lifestyle/anxiety and sex/anxiety, we used the Odds-Ratio (OR).

The results were obtained by calculations performed in the Minitab ${ }^{\circledR}$ software, version 15.1.1.0. The minimum level of significance required to reject the null hypothesis ( $\mathrm{HO}$ ) was set at $\mathrm{p}<0.05$.

\section{RESULTS}

The sample was composed of 144 men (56.2\%) and 112 women $(43.8 \%)$ who practiced physical activity regularly. The sedentary group had 109 men (42.6\%) and 147 women (57.4\%). The sedentary group had an average age of 26.2 , which was considered to be significantly lower in relation to the active group, with an average age of $29(t=3.18 ; p=0.002)$. For the active group, $44.1 \%$ of the sample mentioned the practice of only one type of physical activity, while $47.3 \%$ reported practicing two and $8.6 \%$, three or more types. It is worth mentioning that the practice of bodybuilding, as a complement to physical activity, was reported by $23.4 \%$ of the sample of active individuals. Running was the type of activity most reported by practitioners of physical activity, with $42.7 \%$.

As for the weekly frequency of physical activity, most of the active individuals reported practicing physical activity three times per week (45.7\%), followed by $30.5 \%$ who practiced physical activity five times per week and $23.8 \%$ who practiced four times weekly.

Both in the active and sedentary groups the mean scores of anxiety fall in moderate. Although both the average values (35.9 for active individuals and 42.1 for sedentary) are classified as moderate anxiety by the Spielberger questionnaire, the Student t-test showed a significant difference between the average scores of the groups, i.e., in a confidence interval of 95\% of chance for the difference between the averages, the $t$ value was considered significant (Table 1).

Although there was a difference between the averages of the anxiety scores, they do not represent a clinically relevant difference, since both groups had a mean score compatible with moderate anxiety. To test the relevance, we used the chi-square test $\left(X^{2}\right)$. For 2 degrees of freedom (number of groups - 1) and a significance level of 5\%, the critical value of $X^{2}$ must be greater than or equal to 5.99 to be considered relevant (9). The results showed a significant difference between the groups $\left(X^{2}=105.0 ; p<0.001\right)$. Chart 1 summarizes the distribution of mild, moderate and severe anxiety prevalence in the groups.

The OR results to estimate the association between sedentary lifestyle and anxiety showed a positive correlation of 3.29 between a sedentary lifestyle and intense anxiety scores, i.e., a sedentary individual has approximately three times more chances of having intense anxiety scores when compared to a physically active individual.

TABLE 1. MEAN SCORES OF ANXIETY (IDATE)

\begin{tabular}{l|l|l|l|l}
\multicolumn{5}{l}{ Group } \\
& Active & Sedentary & $\begin{array}{l}\text { Cl 95\% for } \\
\text { difference }\end{array}$ & $\begin{array}{l}\text { T-test } \\
(p-v a l u e)\end{array}$ \\
\hline $\begin{array}{l}\text { Average } \\
\text { Score (SD) }\end{array}$ & $35.9(9.01)$ & $42.1(10.10)$ & $(4.46-7.78)$ & $\begin{array}{l}7.24 \\
(<0.001)\end{array}$ \\
\hline
\end{tabular}




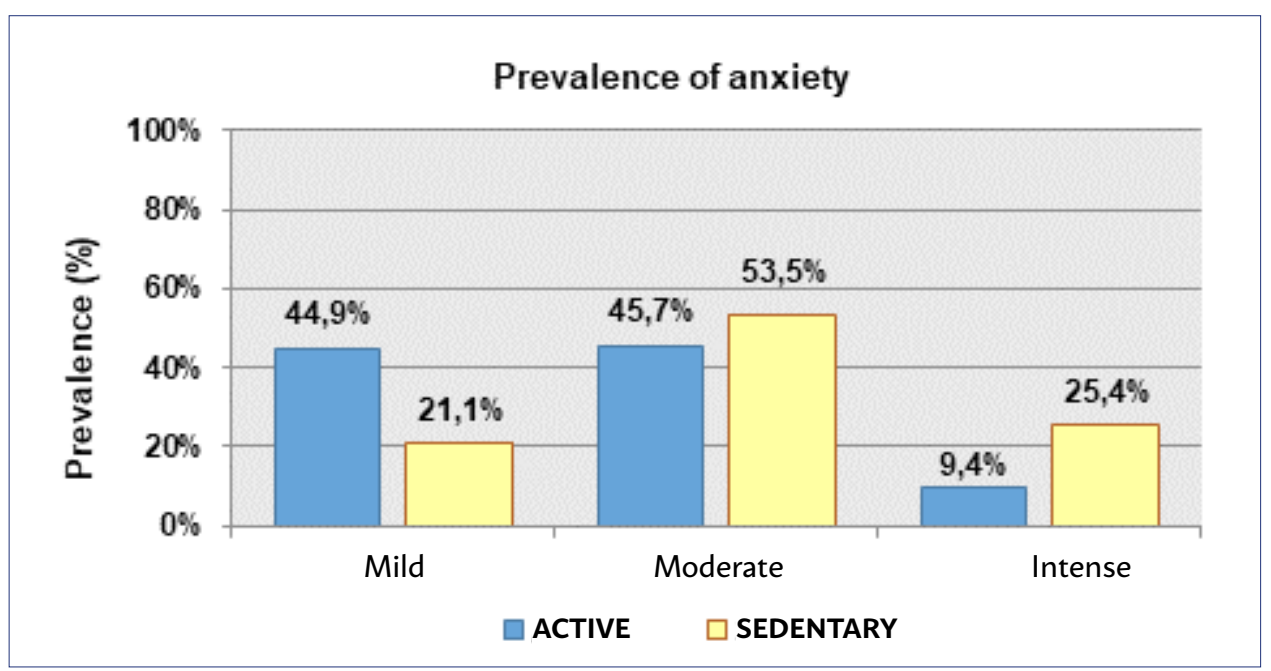

CHART 1.

PREVALENCE OF

ANXIETY

Since the samples were mixed regarding the distribution per sex, the distribution of clinical scores of anxiety per sex was evaluated in both groups. In both groups, there was a higher prevalence in females (OR $=2.83$ for the active group and $\mathrm{OR}=44.42$ for the sedentary group). Both in the active and sedentary groups, women had higher scores of anxiety compared to men. In addition, the prevalence of severe anxiety in sedentary women is much higher if compared with the active ones.

To test the impact of age and the frequency of physical activity practice in the scores, we used the Pearson correlation $(r)$. The results are summarized in Table 2. To be considered significant, the r-value must be greater than 0.3 (positive correlation) or lower than -0.3 (negative correlation). Thus, according to table 2, there was no correlation between age/ anxiety scores and frequency of activity/anxiety scores.

\section{DISCUSSION}

Mens sana in corpore sano. In the 1st century A.D., Juvenal coined the famous phrase, probably from personal observation that physically active individuals had better emotional balance. It took almost 2

TABLE 2. CORRELATIONS BETWEEN AGE/FREQUENCY OF PHYSICAL ACTIVITY AND ANXIETY

\begin{tabular}{l|l|l}
\multicolumn{1}{c}{$\begin{array}{l}\text { Active group } \\
\text { r }\end{array}$} & $\begin{array}{l}\text { Sedentary group } \\
r\end{array}$ \\
\hline Age $x$ anxiety & -0.223 & -0.04 \\
\hline $\begin{array}{l}\text { Frequency of physical activi- } \\
\text { ty } x \text { anxiety }\end{array}$ & 0.013 & --- \\
\hline
\end{tabular}

thousand years for scientific evidence to prove that he was right.

The present study quantified anxiety scores using the State-Trait Anxiety Inventory (STAI) in a sample of practitioners of aerobic physical activity, comparing it to a sample of sedentary, healthy individuals, using unpaired samples.

In the region of Vale do Aço, MG, there are no studies that evaluate the benefits of physical activity practice in combating anxiety, which makes this a pioneer study on the region. Furthermore, the majority of studies published to this day evaluate the benefits of physical activity in individuals with psychiatric disorders or other comorbidities. Thus, this study seeks to provide an innovative focus, evaluating only healthy individuals.

It is worth mentioning a conceptual issue. The focus of this study is the practice of physical activity for health benefits, unlike the practice of high-performance sports, which aims at improved results for competition purposes. It is also important to emphasize that the Spielberger questionnaire was not used with the purpose of defining any diagnosis, but rather to assess the propensity toward anxiety. To define a diagnosis effectively, it is necessary to consider the context in which signs and symptoms occur, the history of the individual and the evaluation of the psychiatrist.

Regarding the distribution of the groups in relation to sex and age, it is believed that there could be significant differences for these variables, which characterize a selection bias. However, when analyzing the data, we did not find such a difference using the chi-square test. Thus, although the samples were not paired per age and sex, the final result was not compromised. 
The Student t-test showed a significant difference between the average anxiety scores of the groups. However, from a clinical point of view, both averages represent a clinical score compatible with moderate anxiety. For clinical relevance, we used the chi-square test to prove the difference between the two groups. The active group had significantly lower scores.

In the present study, we found a higher proportion of sedentary individuals who presented scores of intense anxiety (25.4\%) when compared to those who practiced physical activity (9.4\%). Mild anxiety scores, which can be considered physiological, were proportionally more significant in the active group ( $44.9 \%$ versus $21.1 \%$ of the sedentary group). These results are compatible with those of studies addressing similar themes, such as the Minghelli et al. ${ }^{12}$, who also pointed out positive results of the practice of physical exercises in the reduction of anxiety symptoms.

Favorable results were also found by Stonerock et al. ${ }^{13}$, who conducted a meta-analysis only on randomized clinical trials. In their study, on the effect of physical activity as a treatment for patients with anxiety disorder, they concluded that it is as effective as other modalities of treatment, despite the methodological limitations of some studies.

In the present study, the specific effects of the impact of the intensity of physical activity on anxiety scores were not analyzed. For this variable, there is no consensus in the literature about which intensity is ideal for mental health. While Jayakody et al. ${ }^{14}$ found no relevant differences in their study, Conn ${ }^{15}$, using only healthy individuals, found a greater benefit of exercises of moderate and high intensity in reducing anxiety symptoms.

This study was limited to evaluating practitioners of aerobic physical activity, comparing them with individuals with a sedentary lifestyle. A discussion on the beneficial potential of anaerobic activity, such as the bodybuilding activities, could be interesting. Jayakody et al. ${ }^{14}$ showed that both aerobic and anaerobic physical activity have the capacity to reduce anxiety symptoms, with no difference between the modalities. Therefore, this is a topic to be explored in further investigation.

The data found in this study (higher prevalence of severe and moderate anxiety scores in the sedentary group and higher mild anxiety scores in the active group) can be justified by the fact that mild anxiety propels the individual to action, i.e., physiological, being the most significant clinically severe degree.

In the evaluation of the reasons for prevalence, it was noted that the chance of a practitioner of physical activity having high anxiety scores is three times lower than that of a sedentary individual. Although this is a significant result, we did not find in the literature data that could be compared to these results.

In relation to sex, it was evidenced that women are more prone to higher scores of anxiety. Comparing the sexes, there was a greater prevalence of intense anxiety in females, both for the active group $(\mathrm{OR}=2.83)$ as well as for the sedentary group $(\mathrm{OR}=$ 44.42). Therefore, women present a reduction in anxiety scores with the practice of physical activity. Corroborating this study, Griffiths et al. ${ }^{16}$ also demonstrated the benefits of physical activity on the mental health of women in all age groups studied, including older women. Whereas Herring et al. ${ }^{17}$ reported a decrease in the levels of anxiety in young women who practice physical activity, and this reduction is related to the improvement of self-esteem.

Therefore, among the several current studies, there is sufficient evidence to prove the effectiveness of physical activity in the prevention, control and even in the treatment of anxiety disorders. This study also showed such benefits. What are the physiological mechanisms behind such significant findings?

According to Lissek ${ }^{18}$, and Moylan et al. ${ }^{19}$, the anxiolytic mechanisms of physical activity (PA) are not yet fully understood. However, several hypotheses have been used to explain the observed effects. Abnormalities in the fear conditioning processing are central in the physiopathology of anxiety. The excessive activation of the fear neurocircuit generates a state of chronic stress that can produce a variety of effects, which, in turn, leads to an anxiety disorder ad eternum. These effects include: hyperactivation of the hypothalamus-pituitary-adrenal axis (HPA) and the consequent production of cortisol; increased levels of pro-inflammatory cytokines (interleukins 1 and 6, tumor necrosis factor-alpha, interferon-gamma, among others); reactions of oxidation and free radical production, such as nitric oxide. This chronic proinflammatory state causes a reduction in the levels of neurotrophins, like the brain-derived neurotrophic factor (BDNF), which negatively affects neurogenesis in the brain and its neuroplasticity.

To Asmundson et al. ${ }^{20}$, the PA can regulate the 
HPA axis, reducing the hyperactivity of the sympathetic nervous system (seen in patients with anxiety disorders) and increase the role of the parasympathetic nervous system.

According to Viana and Andrade ${ }^{21}$, PA is able to activate the anti-inflammatory mechanisms, with increased levels of anti-inflammatory cytokines, such as interleukin 1 and 10 receptor antagonist. In addition, regular and moderate PA reduce oxidative stress by increasing the activation of antioxidant enzymes (glutathione peroxidase, superoxide dismutase, and catalase) and increasing the synthesis of mitochondrial uncoupling protein 2 (UCP2), which increases the production of adenosine triphosphate and decreases the production of superoxide.

Moylan et al. ${ }^{19}$ pointed out that the protective effects of PA on neurogenesis have been demonstrated by the increase in the synthesis of neurotrophic factors, including the insulin-like growth factor 1 (IGF-1) and the brain-derived neurotrophic factor (BDNF).

Other hypotheses highlight the anxiolytic effects of PA by modulating anandamide receptors and activating the endocannabinoid system, increasing the levels of circulating endocannabinoids, such as anandamide. ${ }^{22.23}$

The main limitation of this study was that it was not able to get a statistic per group of physical activity, trying to prove which method offers the best benefit.

This study excluded individuals who practiced activity at a frequency of fewer than three times per week, following the criteria of the AHA for defining physically active.

Therefore, the present study was able to prove the initial hypotheses, showing that the regular practice of physical activity is related to lower anxiety scores, which makes Juvenal's saying a two-way street - the body promotes a healthy mind and vice versa.

\section{CONCLUSIONS}

For the population studied, we concluded that practitioners of physical activity have lower anxiety scores.

Both man and woman who are physically active have lower anxiety scores compared by sex in relation to sedentary individuals.

No correlation was observed between the frequencies of activity (three to five times per week) and anxiety scores.

Therefore, we can affirm that the research has proven the initial hypothesis and its results can be used as raw material for future studies. In this sense, the need for defining strategies for encouraging the practice of physical activity becomes evident.

\section{RESUMO}

OBJETIVOS: Comparar escores de ansiedade entre praticantes de atividade física e sedentários, entre homens e mulheres e relacioná-los com frequência de atividade física e idade.

MÉTODOS: Amostra de 256 praticantes de atividade física aeróbica regular foi comparada à amostra de 256 sedentários (grupo controle). Escores de ansiedade foram quantificados por meio do Inventário de Ansiedade Estado-Traço de Spielberger (Idate). Os escores dos grupos foram comparados por meio dos testes t de Student e qui-quadrado para dados paramétricos e não paramétricos, respectivamente. A correlação entre escores de diferentes variáveis foi realizada pelo teste de Pearson.

RESULTADOS: Houve diferença significativa entre os escores médios de ansiedade $(p<0,001)$ e o teste qui-quadrado comprovou haver maior prevalência de escores de ansiedade intensa $(p<0,001)$ no grupo de sedentários. Idade não se correlacionou com piores escores de ansiedade $(p<0,05)$. Em relação ao sexo, mulheres apresentaram maior prevalência de escores de ansiedade intensa.

CONCLUSÕES: Praticantes de atividade física possuem menores escores de ansiedade e ambos os sexos se beneficiam com o potencial ansiolítico da prática de atividade física. Portanto, foi comprovado que a máxima de Juvenal, Mens sana in corpore sano, também pode ser interpretada em sentido inverso, em que um corpo são se correlaciona com uma mente sã.

PALAVRAS-CHAVE: Ansiedade. Exercício. Estilo de vida sedentário. Psiquiatria.

\section{REFERENCES}

1. Ströhle A. Physical activity, exercise, depression and anxiety disorders. | Neural Transm (Vienna). 2009;116(6):777-84.

2. Martínez de Morentin PB, López M. "Mens sana in corpore sano": exercise and hypothalamic ER stress. PLoS Biol. 2010;8(8). pii: e1000464.

3. World Health Organization. Global recommendations on physical activity for health. Geneva: World Health Organization; 2010.
4. Woodcock J, Franco OH, Orsini N, Roberts I. Non-vigorous physical activity and all-cause mortality: systematic review and meta-analysis of cohort studies. Int J Epidemiol. 2011;40(1):121-38.

5. Teychenne M, Costigan SA, Parker K. The association between sedentary behaviour and risk of anxiety: a systematic review. BMC Public Health. 2015;15:513. 
6. Almeida IMD. Prevalência de sintomas de ansiedade e depressão em docentes do curso de Medicina da Universidade Federal da Bahia. [Monografia de Conclusão de Curso de Medicina]. Salvador: Universidade Federal da Bahia; 2013

7. Mochcovitch MD, Deslandes AC, Freire RC, Garcia RF, Nardi AE. The effects of regular physical activity on anxiety symptoms in healthy older adults: a systematic review. Braz J Psychiatr. 2016;38(3):255-61.

8. Portney LG, Watkins MP. Foundations of clinical research: applications to practice. $3^{\text {rd }}$ ed. New Jersey: Pearson Prentice Hall; 2009. p.912.

9. Motta VT. Bioestatística. $2^{2}$ ed. Caxias do Sul: EDUCS; 2006

10. American Heart Association. American Heart Association recommendations for physical activity in adults. 2016. [cited 2018 May 5]. Available from: https://www.heart.org/en/healthy-living/fitness/fitness-basics/ aha-recs-for-physical-activity-in-adults

11. Andrade L, Gorenstein C, Vieira Filho AH, Tung TC, Artes R. Psychometric properties of the Portuguese version of the State-Trait Anxiety Inventory applied to college students: factor analysis and relation to the Beck Depression Inventory. Braz | Med Biol Res. 2001;34(3):367-74.

12. Minghelli $B$, Tomé $B$, Nunes $C$, Neves $A$, Simões $C$. Comparação dos níveis de ansiedade e depressão entre idosos ativos e sedentários. Rev Psiq Clín. 2013;40(2):71-6

13. Stonerock GL, Hoffman BM, Smith P|, Blumenthal |A. Exercise as treatment for anxiety: systematic review and analysis. Ann Behav Med. 2015;49(4):542-56

14. Jayakody K, Gunadasa S, Hosker C. Exercise for anxiety disorders: systematic review. Br J Sports Med. 2014;48(3):187-96.
15. Conn VS. Anxiety outcomes after physical activity interventions: meta-analysis findings. Nurs Res. 2010;59(3):224-31.

16. Griffiths A, Kouvonen A, Pentti J, Oksanen T, Virtanen M, Salo P, et al. Association of physical activity with future mental health in older, mid-life and younger women. Eur | Public Health. 2014;24(5):813-8.

17. Herring MP, O'Connor PJ, Dishman RK. The effect of exercise training on anxiety symptoms among patients: a systematic review. Arch Intern Med. 2010;170(4):321-31

18. Lissek S. Toward an account of clinical anxiety predicated on basic, neurally mapped mechanisms of Pavlovian fear-learning: the case for conditioned overgeneralization. Depress Anxiety. 2012;29(4):257-63.

19. Moylan S, Eyre HA, Maes M, Baune BT, lacka FN, Berk M. Exercising the worry away: how inflammation, oxidative and nitrogen stress mediates the beneficial effect of physical activity on anxiety disorder symptoms and behaviours. Neurosci Biobehav Rev. 2013;37(4):573-84.

20. Asmundson G], Fetzner MG, Deboer LB, Powers MB, Otto MW, Smits A. Let's get physical: a contemporary review of the anxiolytic effects of exercise for anxiety and its disorders. Depress Anxiety. 2013;30(4):362-73.

21. Viana MC, Andrade LH. Lifetime prevalence, age, and gender distribution and age-of-onset of psychiatric disorders in the São Paulo Metropolitan Area, Brazil: results from the São Paulo. Megacity Mental Health Survey. Rev Bras Psychiatr. 2012;34(3):249-60.

22. Dietrich A, McDaniel WF. Endocannabinoids and exercise. $\mathrm{Br}$ | Sports Med. 2004;38(5):536-41.

23. Dworak M, Diel P, Voss S, Hollmann W, Strüder HK. Intense exercise increases adenosine concentrations in rat brain: implications for a homeostatic sleep drive. Neuroscience. 2007;150(4):789-95. 